\title{
THE RELATIONSHIP BETWEEN EMOTIONAL INTELLIGENCE AND STRESS MANAGEMENT
}

\section{Authors:}

Saras Ramesar ${ }^{1}$

Pieter Koortzen ${ }^{2}$

Rudolf M. Oosthuizen ${ }^{1}$

\section{Affiliations:}

${ }^{1}$ Department of Industrial and Organisational

Psychology, University of

South Africa, South Africa

${ }^{2}$ Resolve Encounter

Consulting, South Africa

Correspondence to:

Rudolf M. Oosthuizen

e-mail:

oosthrm@unisa.co.za

Postal address:

PO Box 392, UNISA 0003 ,

South Africa

\section{Keywords:}

emotional competence;

social intelligence; stress management skills;

Occupational Personality Questionnaire (OPQ32i);

Emotional Quotient

Inventory (EQ-i)

\section{Dates:}

Received: 30 Apr. 2008

Accepted: 26 Sept. 2008

Published: 05 May 2009

How to cite this article: Ramesar, S., Koortzen, P., \& Oosthuizen, R.M. (2009). The relationship between emotional intelligence and stress management. SA Journal of Industrial Psychology/SA Tydskrif vir Bedryfsielkunde, 35(1), Art. \#443, 10 pages. DOI: 10.4102/sajip.v35i1.443

This article is available at:

http://www.sajip.co.za

(C) 2009. The Authors. Licensee: OpenJournals Publishing. This work is licensed under the Creative Commons Attribution License.

\section{ABSTRACT}

Regardless of where one lives in the world, one cannot escape three defining forces of our time: globalisation, the information revolution and the speed of change (Cascio, 2001). To ensure continued organisational performance and to maintain the competitive advantage, organisations must therefore constantly implement changes in strategy, structure, process and culture (Higgs, 2002; Langley, 2000). Goleman (1998) proposes a solution of self-awareness as a key skill in handling stress, thereby indicating that a lack of emotional intelligence in such an unstable environment means possible failure that can impact on everyone's future. The general aim of this research was to determine whether there is a relationship between emotional intelligence and stress management in a group of managers. This was done through a quantitative study of the relationship between stress management and emotional intelligence. These constructs were operationalised by means of a combination of scales present in the Feelings and Emotions domain of the Occupational Personality Questionnaire (OPQ32i) and the Emotional Quotient Inventory (Bar-On EQ-i). The correlation and regression results seem to indicate that stress management (the ability to cope with stress) is a component of emotional intelligence, while stress can be either an input or an outflow of emotional intelligence or the lack thereof.

\section{INTRODUCTION}

Organisations have to survive in an environment characterised by increased global competition, ongoing developments in organisations, a relentless drive for greater cost-effectiveness, tightly controlled budgets and increased competitiveness in the workplace. Furthermore, the restructuring of organisations, ongoing technological revolutions, market changes, higher levels of unemployment, deregulation, privatisation, mergers, acquisitions, the movement of labour towards less expensive economic locations and the empowerment of consumers, coupled with changes in demand patterns, create added pressures in the working environment. As a result, organisations constantly have to implement changes in strategy, structure, process and culture to ensure continued organisational performance and to maintain the competitive advantage (Higgs, 2002; Langley, 2000). Significant challenges to and forces on South African organisations are the introduction of new business strategies and new management systems, increases in labour costs, changes in technology and government policy (Vermeulen, 2002).

These challenges to and changes in organisations can result in, among others, retrenchments, downsizing, multitasking and restructuring. Some of the problems associated with these changes are job insecurity, increased stress, the loss of competent employees and increased workload (Goleman, Boyatzis \& McKee, 2002; Rees, 1997). Change is thus not only about the implementation of new systems and processes but also about the people within this environment: how the individuals behave, what they think, how they interact with their fellow employees, their perceptions and their ability to handle the changing environment (Ndlouvu \& Parumasur, 2005).

Major changes have occurred over recent years, such as hyperinflation, political turmoil, new mergers and coalitions, new technologies and new rules. These changes place a strain on all employees, managers included. It is not experience but adaptability that remains crucial (Goleman, 1998; Hellgren, Naswell \& Sverke, 2005). 'In a business culture which puts more and more pressure on us to succeed, it is vital to control and manage stress' (Grout, 1994, p. 30). However, organisations tend to focus on the symptoms of stress and not the causes and this can exacerbate the stressful situations in which managers may find themselves (Rees, 1997). Self-awareness is thus a key skill in handling stress, as are emotional intelligence competencies, such as stress management and adaptability. A lack of emotional intelligence in such an unstable environment means possible failure and this can impact on everyone's future (BarOn, 1997; Goleman, 1998).

The researchers' observations indicate that organisations tend to utilise management programmes that focus on the theory of stress, its symptoms and its reactions rather than attempting to pre-empt the reactions of stress by encouraging an awareness of emotional intelligence as a prerequisite to understanding these reactions to stress. Individuals with higher emotional clarity and repair experience fewer negative emotional responses and intrusive thoughts after an acute stressor, which enables them to adapt more readily to the experience (Ramos, Fernandez-Berrocal \& Extremera, 2007). It can therefore be advantageous to study the relationship between emotional intelligence and stress in an attempt to assist managers in their development and stress management. Developers of management programmes should be encouraged to incorporate findings on emotional intelligence and stress management in their course material so as to alleviate stress in organisations (Mikolajczak \& Luminet, 2008).

Furthermore, in researching theories on emotional intelligence and its relationship to stress management, the researchers were unable to find many theoretical and empirical studies that pertained solely to these two constructs. Studies conducted with nurses and nursing students show that emotional intelligence is a skill that minimises the negative stress consequences. The results indicate positive correlations between clarity and social support, social support and repair, and social support and well-being. Clarity and 
emotional repair are predictors of social support and emotional repair is the main predictor of well-being. These results show the importance of perceived emotional intelligence in stress management (Montes-Berges \& Augusto, 2007). 'Managing our emotions, and relating to others, are among the greatest challenges that we face in life' (Lopes \& Salovey, 2004, p. 299). However, 'it is worth acknowledging that we are only beginning to learn about emotional intelligence' (Mayer, Cobb \& Casey, $2000 a$, p. 278) and therefore 'future research will clarify the importance of specific, social, emotional and practical skills for adaptation over the life course' (Lopes \& Salovey, 2004, p. 300).

Both the public and academia remained mostly unaware of emotional intelligence until 1995, when Daniel Goleman popularised the construct in his trade book, Emotional intelligence: Why it can matter more than IQ. Emotional intelligence quickly captured the interest of the media, general public and researchers (Salovey, Brackett \& Mayer, 2004). Emotional intelligence and emotional quotient (EQ) were, in fact, selected as the most useful new words or phrases of 1995 by the American Dialect Society and, from there, the concept of emotional intelligence made it to the cover of Time magazine (Mayer, Salovey \& Caruso, 2000b). Following shortly behind this development, Bar-On (1997) introduced his work on emotional intelligence and this led to the 1990s being flooded with work by Goleman (1998), Bar-On (1997) and Mayer and Salovey (1997), who proved emotional intelligence as a type of ability.

According to Salovey and Mayer (1990), emotions are organised responses that cross psychological subsystems, which include the physiological, cognitive, motivational and experiential systems. Emotions within an individual, both positive and negative, arise from a response to either an internal or an external event. Emotions can be distinguished from the closely related concept of moods in that emotions are shorter and generally more intense.

With regard to intelligence, the most often cited definition is Wechsler's statement that 'intelligence is the aggregate of global capacity of the individual to act purposefully, to think rationally, and to deal effectively with his environment' (Salovey \& Mayer, 1990 , p. 3). Closely overlapping the construct of emotional intelligence are the constructs of social intelligence, alexithymia (Salovey \& Mayer, 1990; Taylor \& Bagby, 2000), affective orientation (Taylor \& Bagby, 2000), emotional competence (Saarni, 2000) and psychological mindedness (McCallum \& Piper, 2000). It is apparent that the evolution of the definition of emotional intelligence is echoed in the various definitions of these constructs.

The construct of alexithymia, for example, refers to difficulty in identifying and distinguishing bodily sensations of emotional arousal and difficulty in describing feelings. The construct of affective orientation refers to the extent to which people are aware of their emotions. The construct of emotional competence is defined as a demonstration of capacity and skill in eliciting emotional-social transactions and is regarded more as a transaction than a characteristic. The definitions of alexithymia, affective orientation and emotional competence parallel the definition of emotional intelligence, incorporating the aspects of thinking, feeling, being aware and expressing emotions as defined by Mayer and Salovey (1997) and Goleman (1998).

Attempting a more holistic approach and a move towards the definition of emotional intelligence are the constructs of social intelligence and psychological mindedness. The construct of social intelligence incorporates the ability to think, feel and behave in order to achieve social tasks while functioning in a social environment. The construct of psychological mindedness is more encompassing and refers to the desire to learn the possible meanings and causes of both internal and external experiences as well as to the ability to look inwards rather than only outwards at environmental factors, thus allowing the conceptualisation of the relationship across thoughts, feelings and actions within an environment. The constructs of social intelligence and psychological mindedness are therefore closer to the definition of emotional intelligence as defined by Bar-On (1997) below because they incorporate the concepts of thinking, feeling and actions within a certain environment.

\section{Theoretical foundation of the Bar-On model}

Darwin's early work on the importance of emotional expression for survival and adaptation (1872/1965) has influenced the ongoing development of the Bar-On model, which both stresses the importance of emotional expression and views the outcome of emotionally and socially intelligent behaviour in Darwinian terms of effective adaptation. Additional influence on this thinking can be traced to Thorndike's description of social intelligence and its importance for human performance (1920) and to Wechsler's observations relating to the impact of noncognitive and conative factors on what he refers to as 'intelligent behaviour' $(1940 ; 1943)$. Sifneos' description of alexithymia (1967) on the pathological end of the emotional-social intelligence (ESI) continuum and Appelbaum's conceptualisation of psychological mindedness (1973) on the eupsychic end of this continuum have also impacted on the ongoing development of the Bar-On model (Bar-On, 2006).

From Darwin to the present, most descriptions, definitions and conceptualisations of ESI include one or more of the following key components: (a) the ability to recognise, to understand and to express emotions and feelings; (b) the ability to understand how others feel and to relate to them; (c) the ability to manage and to control emotions; (d) the ability to manage change, to adapt and to solve problems of both a personal and an interpersonal nature; and (e) the ability to generate positive affect and to be self-motivated (Bar-On, 2006).

The Bar-On model provides the theoretical basis for the emotional quotient inventory (EQ-i) instrument, which was originally developed to assess various aspects of this construct and to examine its conceptualisation. According to this model, ESI is a cross-section of interrelated emotional and social competencies, skills and facilitators that determine how effectively we understand and express ourselves, understand others and relate to them, and cope with daily demands. The emotional and social competencies, skills and facilitators referred to in this conceptualisation include the five key components described above, each of these components, in turn, also comprising a number of closely related competencies, skills and facilitators. Consistent with this model, to be emotionally and socially intelligent is effectively to understand and express oneself, to understand and relate well to others, and to cope successfully with daily demands, challenges and pressures. This is based, first and foremost, on one's intrapersonal ability to be aware of one's feelings, to understand one's strengths and weaknesses and to express one's feelings and thoughts nondestructively. On the interpersonal level, being emotionally and socially intelligent encompasses the ability to be aware of others' emotions, feelings and needs and to establish and maintain cooperative, constructive and mutually satisfying relationships. Ultimately, being emotionally and socially intelligent means to manage personal, social and environmental change effectively by realistically and flexibly coping with the immediate situation, solving problems and making decisions. To do this, people need to manage emotions so that their emotions work for them and not against them and to be sufficiently optimistic, positive and self-motivated (Bar-On, 2006).

Bar-On (1997) defines emotional intelligence as an array of non-cognitive capabilities, competencies and skills. These influence one's ability to cope with environmental demands and pressures. The researcher has adapted the model to a table format in Figure 1 to facilitate reading (Bar-On, 2000, p. 365). 
A description of the emotional intelligence model of BarOn comprises five scales with fifteen subscales. These are comprising self-regard, emotional awareness, assertiveness, independenceand self-actualisation; comprising empathy, social responsibility and interpersonal relationships; comprising stress tolerance and impulse control; comprising reality testing, flexibility and problem solving; and comprising optimism and happiness (Bar-On, 2000). The description of each of the scales is presented in Figure 1 below. According to McCallum \& Piper (2000), the model proposed by Bar-On is perhaps the clearest and most comprehensive to date.

The model of emotional intelligence by Bar-On (1997) can be summarised as follows:

- The model comprises the intrapersonal, interpersonal, stress management, adaptability and general mood scales

- The scales of stress management, adaptability and general mood are unique to the model

- The model maps more clearly onto the five-factor model

- Its definition offers the context of environment.

\section{Theoretical conceptualisation of stress management}

In a survey conducted at an international hotel chain, it was found that interactions with superiors led to most feelings of frustration, disappointment, anger, sadness, disgust or stress. The art of emotional leadership includes the completion of real work demands without unduly upsetting others (Goleman et al., 2002). One of the oldest laws in psychology holds that, beyond a moderate level, increases in anxiety and worry erode mental abilities. Distress not only wears away at mental abilities but also makes people less emotionally intelligent (Yang \& Gu, 2007). People who are upset thus have trouble reading emotions in others accurately, thereby decreasing their social skills. Another consideration is that, according to a new finding on job satisfaction, the emotions that people feel while they work reflect their quality of work - when people feel good, they work at their best with increased levels of mental efficiency and hence demonstrate a more positive outlook. In a sense, managers who spread bad moods are no good for business, while managers who spread good moods enhance productivity and hence business success (Jamali, Sidani \& Abu-Zaki, 2008; Mikolajczak, Menil \& Luminet, 2007a).

Leaders often feel unsafe and as if they are under a microscope because their every action is scrutinised. This inhibits risk taking and experimentation. In both this and other ways, leadership therefore becomes very stressful. Early studies show that, when people have a drive for power, that very desire for power has the same arousing effect as that of being under actual biological stress. When a person's stress levels increase, however, the body's stress hormones are released, thus hampering learning.

Learning for leadership therefore works best under conditions where people feel safe (Goleman et al., 2002). Furthermore, those who react with hardiness and who see work as exciting and as a chance to develop rather than seeing work as an enemy bear the burden of stress much better, indicating that, with the right emotional resources, that which seems threatening can be handled as a challenge and can be met with energy and enthusiasm (Goleman, 1998).

In 'bearing the burden of stress much better', it is crucial to understand stress. All living organisms experience stress. Stress is perceived by individuals in the context of their own experience. It is a product of being alive. The term 'stress' refers to a pressure or demand that is placed on an organism to adapt or adjust (Nevid, Rathus \& Greene, 2005). In essence, stress is any event that places a demand on the body, whether mentally or physically. (In this study, the term 'cope' is used interchangeably with the term 'manage'.) According to Lazarus and Folkman (1984), coping refers to one's efforts to manage or control a situation that is viewed as either stressful, overtaxing or challenging to one's personal coping resources. Furthermore, implicit in most descriptions of coping is the notion of effectiveness (Matthews \& Zeidner, 2000).

\begin{tabular}{|c|c|}
\hline SCALE & DESCRIPTION OF THE SCALE \\
\hline \multicolumn{2}{|l|}{ Intrapersonal EQ } \\
\hline Self-regard (SR) & is the ability to be aware of, understand, accept and respect oneself. \\
\hline Emotional self-awareness (ES) & is the ability to recognise and understand one's emotions. \\
\hline Assertiveness (AS) & is the ability to express feelings, beliefs and thoughts and to defend one's rights in a non-destructive manner. \\
\hline Independence (IN) & is the ability to be self-directed and self-controlled in one's thinking and actions and to be free of emotional dependency. \\
\hline Self-actualisation (SA) & is the ability to realise one's potential and to do what one wants to do, enjoys doing and can do. \\
\hline \multicolumn{2}{|l|}{ Interpersonal EQ } \\
\hline Empathy (EM) & is the ability to be aware of, understand and appreciate the feelings of others. \\
\hline Social responsibility (RE) & is the ability to demonstrate oneself as a cooperative, contributing and constructive member of one's social group. \\
\hline Interpersonal relationship (IR) & $\begin{array}{l}\text { is the ability to establish and maintain mutually satisfying relationships that are characterised by emotional closeness, intimacy and } \\
\text { giving and receiving affection. }\end{array}$ \\
\hline \multicolumn{2}{|l|}{ Stress-management EQ } \\
\hline Stress tolerance (ST) & $\begin{array}{l}\text { is the ability to withstand adverse events, stressful situations and strong emotions without 'falling apart' by actively and positively } \\
\text { coping with stress. }\end{array}$ \\
\hline Impulse control (IC) & is the ability to resist or delay an impulse, drive or temptation to act and to control one's emotions. \\
\hline \multicolumn{2}{|l|}{ Adaptability EQ } \\
\hline Reality testing (RT) & $\begin{array}{l}\text { is the ability to assess the correspondence between what is experienced internally and subjectively and what exists externally and } \\
\text { objectively. }\end{array}$ \\
\hline Flexibility (FL) & is the ability to adjust one's feelings, thoughts and behaviour to changing situations and conditions. \\
\hline Problem solving (PS) & is the ability to identify and define personal and social problems and to generate and implement potentially effective solutions. \\
\hline \multicolumn{2}{|l|}{ General-mood EQ } \\
\hline Optimism (OP) & is the ability 'to look on the brighter side of life' and to maintain a positive attitude, even in the face of adversity. \\
\hline Happiness (HA) & is the ability to feel satisfied with one's life, to enjoy oneself and others and to have fun and express positive emotions. \\
\hline
\end{tabular}


According to Cox (1985), coping is a form of problem-solving behaviour, while stress is the result of failed problem solving. Coping involves cognitive and behavioural strategies and represents either an adjustment to a situation or an adjustment of a situation. Coping is regarded as successful if the source of the problem is dealt with or if the experience of the stress is directly reduced. The researchers' conceptualisation of stress and its management therefore includes:

- the existence of a situation that is viewed as stressful or challenging to a person's personal coping resources

- the utilisation of cognitive and behavioural strategies by a person to solve a problem effectively

- a person's efforts to manage a problem effectively as measured by the reduction of stress

- stress being viewed by the researchers as internal demands that exceed personal resources, while coping being viewed as emphasising psychological strengths that enable a person to cope with stress (Pike, 2003; Strümpfer, 2003).

According to Zeidner and Saklofske (1996), coping in current psychological writings is viewed as an active process and as interacting with factors such as personality and stressmanagement skills. This view is supported by the developers of the Occupational Personality Questionnaire (OPQ), which indicates that certain combinations of extreme OPQ dimensions can be indicative of a generalised vulnerability and increased susceptibility to the negative effects of stress. Conversely, a greater degree of resilience can be inferred from the opposite trends in scores (bipolar). This relates to findings described by the 'Hardy Personality' and 'Type A and B' behaviour. The OPQ model is illustrated in Figure 2 (SHL, 1999a).

It can be seen from Figure 2 that personality is concerned with three main domains. The first of these, namely the relating domain, refers to how an individual relates to others. It is characterised by traits such as assertiveness, outgoingness and empathy. The thinking domain refers to how an individual typically thinks and includes traits such as conservatism, abstract thinking and detail consciousness. The domain of feeling refers to emotions such as anxiety, tough-mindedness and optimism. There is potentially a fourth area - the energies domain - which comprises traits such as vigour, competitiveness and decisiveness. The energies domain does, however, impinge on the other domains (SHL, 1999a).

Particularly relevant to this study are the dimensions relating

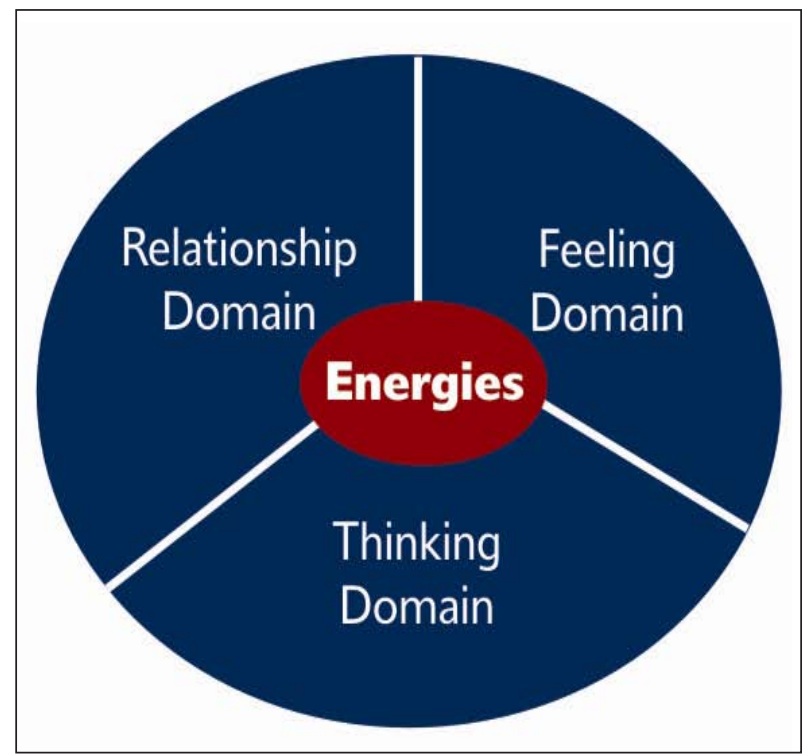

FIGURE 2

OPQ Model of Personality to general levels of anxiety and tension, proneness to worry excessively about specific events, sensitivity to criticism and hostility, optimism versus pessimism, and self-confidence or self-esteem. From these dimensions, it can be deduced that the following OPQ traits are applicable: 'relax', 'worrying', 'tough minded', 'optimistic' and 'socially confident'.

In integrating emotional intelligence and stress management, it is important to note that individuals who react to stress with hardiness, who see work as strenuous but exciting and who see change as a chance to develop rather than as an enemy bear the physical burden of stress much better and experience fewer illnesses. A paradox of working life is that situations are viewed differently. Some might see something as a devastating threat, while others might view it as an invigorating challenge. With the right emotional resources, what might seem threatening can be viewed instead as a challenge and be met with enthusiasm, thus allowing the brain to generate different chemicals. Chemicals that respond to stress and threat are different from those that respond to enthusiasm (Goleman, 1998).

As a person's stress increases, the body reacts by secreting more adrenaline and noradrenaline, the body's stress hormones. Simultaneously, cortisol is secreted, which lasts even longer than adrenaline and, in addition, interferes with learning. This is exacerbated when stress is high and sustained as cortisol secretion continues, hampering learning by destroying essential brain cells in the hippocampus (Goleman et al., 2002).

In this study, the researchers focused specifically on the relationship between these two constructs in a managerial sample. The literature provided the following insights on the impact of the two constructs on the functioning of the manager or leader and on her or his subordinates. Goleman et al. (2002) state that a bad relationship with a manager can, for example, leave a person with distress, a mind that is preoccupied and a body that is unable to calm itself. Such negative emotions, especially chronic anger, anxiety or a sense of futility, can cause a disruption of work and of the task at hand. This can result in employees who are not upbeat and who do not have the drive to ensure customer satisfaction, which, in turn, can result in declining revenues.

Acknowledging that people work best when they feel good is crucial. It tends to make them feel more optimistic and enhances their mental efficiency, ensuring better understanding of information, flexible thinking, the ability to use good judgement in decision making, and creativity (Goleman et al., 2002). Employees who feel relaxed are more likely to ensure customer satisfaction, thus ensuring the long-term sustainability and profit generation of the organisation (Mikolajczak, Roy, Luminet, Fillée \& De Timary, 2007b).

Throughout history and in all cultures, the leader in any group is the one to whom others look for assurance and clarity when facing uncertainty or a threat, or when there is a job to be done. The leader tends to act as the group's emotional guide. In the modern organisation, this primordial emotional task - although, by now, largely invisible - remains foremost among the many jobs of leadership in that it drives collective emotions in a positive direction and clears the atmosphere created by negative emotions (Hopkins, O'Neil \& Williams, 2007). This task applies to leadership everywhere, from the boardroom to the shop-floor. Quite simply, in any human group, the leader has maximum power to sway everyone's emotions. If people's emotions are pushed towards the range of enthusiasm, performance can soar; if people are driven towards chaos and anxiety, they can become unsettled. When leaders drive emotions positively, they bring out everyone's best. When they drive emotions negatively, they cause dissonance, undermining the emotional foundations that allow people to excel. Whether an organisation withers or flourishes depends to a remarkable 
extent on the leader's effectiveness in this primal emotional dimension (Goleman et al., 2002)

Furthermore, it is leaders who give praise or withhold it, criticise or not, offer support or not, guide people in the sense that they have clarity and direction, encourage flexibility and allow people free rein to do their best to get the job done or not. People thus take their emotional cues from their leaders (Goleman et al., 2002). Understanding emotions includes the ability to recognise relationships between emotions, to determine the meanings that emotions convey, to understand complex feelings and to recognise how emotions change from one state to another. Understanding emotions is the ability that provides a leader with the information on what makes people tick. This is the ability that provides a leader with an understanding of other people's points of view (Caruso, Mayer \& Salovey, 2002).

One of the oldest laws in psychology holds that, beyond a moderate level, increases in anxiety and worry erode mental abilities. Distress not only erodes mental abilities but also makes people less emotionally intelligent. People who are upset have trouble reading emotions in other people accurately - decreasing the most basic skill needed for empathy and, as a result, impairing their social skills (Goleman et al., 2002). Keeping our distressing emotions in check is the key to emotional well-being (Goleman, 1995) and successful coping with stressful encounters is central to any construct of emotional intelligence (Matthews \& Zeidner, 2000).

\section{Aim of the research}

The general aim of this research was to determine whether there is a relationship between emotional intelligence and stress management in a group of managers. This was done using the research design discussed below.

The hypothesis can be formulated as follows: There is no relationship between emotional intelligence and stress management.

\section{RESEARCH DESIGN}

\section{Research approach}

The research was a descriptive study aimed at quantitatively testing the hypothesis that a significant relationship exists between emotional intelligence and stress management by utilising measuring instruments that are capable of measuring the related factors.

\section{Participants}

In order to have as large a sample as possible, a list of all employees who were considered for managerial positions was obtained from the personnel department in a South African financial institution. A total of 142 names was received. The realised sample, however, was 105 due to a lack of response from some employees, resignations, incomplete information and employees who declined to partake in the study. This method of sampling falls under the category of non-probability sampling, which means that the probability of a respondent being chosen is unknown. The advantage of the method is that it is not complicated and allows one to draw information from respondents who are available at the time. The disadvantage is that, as a result, the final sample may not be fully representative and results may not be entirely generalisable to the population from which the sample is drawn (Babbie, 1986; Bailey, 1987).

\section{Measuring instruments}

\section{Occupational Personality Questionnaire 32i (OPQ32i)}

Rationale: The OPQ32i structure is based on the hypothesis that personality is concerned with three main areas, namely the relating domain, the thinking domain and the feeling domain.
There is also a possible fourth domain, the energies domain. The normative item set was used in addition to the scale descriptions as an indicator of the ipsative item content. This helped to ensure the similarity of content between the ipsative and normative questionnaires.

Dimensions, administration and interpretation: The item pattern of OPQ32i places items in blocks of four (quads). In each block of four, the task is to choose the item 'most like you' and the item 'least like you' (SHL, 1999b). The design has a total of 104 blocks of 4 items (416 items in total). Each scale has 13 items (i.e. 13 × 32 = 416). The item pattern is balanced to ensure that items from one scale will only be in the same block of four as an item from any other scale once or twice throughout the whole questionnaire (SHL, 2006).

Reliability: Parallel or alternate-form reliability looks at the agreement between two parallel forms of a questionnaire. A parallel-form estimate of reliability requires two versions of a questionnaire that measure the same constructs through the same approach. Although two versions of the OPQ32i do not exist, SHL conducted this measure using the OPQ32n because both the OPQ32n and the OPQ32i attempt to measure the same constructs (SHL, 1999b). Both tests were completed in the same test session, the correlations ranging from 0.45 to 0.79 with a median of 0.66 . This shows a strong relationship between the scores on the two versions (SHL, 2006).

Internal consistency is the measure of the consistency with which a set of questionnaire items is answered. Cronbach's coefficient alpha was used as a method of assessing internal consistency, with high values indicating a greater degree of accuracy in the scores, as well as generally more homogeneous scale content (SHL, 1999b). Reliability coefficients of 0.60 to 0.80 are generally considered as the minimum acceptable level for personality. If reliability drops below 0.7 for abilities, however, scores become less stable and differentiate less effectively (SHL, 2006). The internal-consistency reliability study was conducted on the OPQ32i. The internal consistencies range from 0.67 to 0.88 , with a median of 0.81 . The sten score is around 1 (SHL, 1999b; SHL, 2006).

Validity: Various aspects of validity include face validity, content validity, criterion-related validity and construct validity (SHL, 1999b).

Face validity is the degree to which a test or questionnaire appears to the untrained eye to have relevance to a particular job (e.g. line manager or candidate). The OPQ32 questionnaires have good face validity for occupational use, as the relevance of the questions and the scales to the style of performance can be seen by both candidates and managers (SHL, 2006).

Content validity refers to the similarity between the context of a questionnaire scale and the domain that it is designed to measure (SHL, 1999b). The inductive approach, which is more conducive to content validity, was used to develop the OPQ questionnaires. Furthermore, job analytical techniques were used to define the domains to be measured, resulting in high content validity (SHL, 2006).

Criterion-related validity in occupational terms is the relationship between a score on a questionnaire and a measure of performance in a job. Many criterion-validity studies are based on the OPQ Concept model rather than on the OPQ32 instruments (SHL, 1999b). There is, however, a strong relationship between the two instruments. The correlational studies resulted in 25 scales of or above 0.7 , with most above 0.8 . The remaining OPQ32 scales correlated between 0.4 and 0.6 with the original Concept scales. The criterion-related results of the OPQ32 questionnaires are thus supported by the Concept model studies (SHL, 2006). 
Construct validity is the extent to which a scale measures a particular hypothetical construct or trait. This is the most abstract form of validity and, from a theoretical point of view, the most basic. In order to build a picture of construct validity, many forms of evidence are required, including the forms of validity discussed above and the intercorrelation patterns of scales within the questionnaire, factor structures, and correlations with other instruments. The focus of such evidence can be either convergent evidence (relationships occurring where expected) or divergent evidence (the absence of relationships where not expected) (SHL, 1999b). Some of the results of the intercorrelation patterns of scales within the questionnaire, factor structures and correlations with other instruments, according to the SHL OPQ32 Manual $\mathcal{E}$ User's Guide (1999), are that the scale intercorrelations range from -0.36 to 0.58 with $82 \%$ falling between -0.1 and 0.1 for the OPQ32i for the general population ( $\mathrm{n}=807$ ). Based on the OPQ32n scale intercorrelations, factor analysis was performed for the general population ( $n=2028$ ). Five factors (as per the Big 5 model of personality), namely extraversion, agreeableness, neuroticism, openness to experience and conscientiousness, were extracted, explaining $48 \%$ of the total variance in the data set. Even though the OPQ32n scale - not the OPQ32i scale - was used in this study, correlations range between 0.45 and 0.79 (SHL, 2006)

\section{Emotional Quotient Inventory (EQ-i)}

Rationale: According to Bar-On (2000), the EQ-i was originally constructed to examine empirically a theory of psychological well-being. What has been developed is a theoretically eclectic and multi-factorial approach to describe operationally and assess quantitatively the complex interrelated concepts of the non-cognitive competencies and skills that influence one's ability to cope with life and to achieve psychological well-being (Van Rooyen \& Partners, 2000).

Dimensions, administration and interpretation: It comprises 133 brief items and employs a 5-point Likert scale ranging from 'very seldom' or 'not true of me' to 'very often true of $\mathrm{me}^{\text {' or }}$ 'true of me'. It takes 30 to 40 minutes to complete, although there is no formal time limit. The EQ-i is suitable for individuals of 16 years and older. It renders a total EQ score, consisting of five composite scale scores namely (1) the intrapersonal composite scale, (2) the interpersonal composite scale, (3) the adaptability composite scale, (4) the stress-management composite scale and (5) the general-mood composite scale, comprising fifteen subscale scores (Bar-On, 2000).

Reliability: With regard to the reliability of the EQ-i, two basic types of reliability studies were conducted on the EQ-i, namely internal consistency and re-test reliability. The Cronbach alpha coefficients are high for all the sub-scales. The coefficients range from a low of 0.69 (social responsibility) to a high of 0.86 (selfregard), with an overall average internal consistency of 0.76 . This indicates very good reliability (Bar-On, 2000; Van Rooyen \& Partners, 2000). Re-test reliability refers to the temporal stability of the instrument over time. Two South African groups were re-tested, one group after one month and the second after four months. The average re-test reliability coefficient after one month was 0.85 and, after four months, 0.75 (Bar-On, 2000; Van Rooyen \& Partners, 2000).

Validity: Furthermore, the inventory includes the following four validity indicators, namely omission rate (the number of omitted responses), inconsistency index (the degree of inconsistency across similar types of items), positive impression (the tendency to give an exaggerated positive response) and negative impression (the tendency to give an exaggerated negative response). The EQ-i has a built-in correction factor that automatically adjusts the scale scores. This is an important feature for self-report measures in that it reduces the distorting effects of social-response bias, thereby increasing the accuracy of the results obtained (Bar-On, 2000).
Nine types of validity studies were conducted, namely content, face, factor, construct, convergent, divergent, criterion group, discriminant and predictive. These studies resulted in the EQ-i demonstrating good construct validity, more than adequate convergent validity, and more than satisfactory predictive validity and divergent validity. With respect to discriminant validity, it was observed that the EQ-i was successful in making significant and often fine differentiations among levels of coping with environmental demands, pressures and general emotional functioning for the population studies. Research on special groups is pertinent to criterion validity and the profiles of various groups were therefore all considered for criteriongroup validity. With regard to content and face validity, numerous series of item analyses were conducted to select the best items for inclusion in the final form of the inventory. In order to examine the factorial structure of the EQ-i, factor analysis was used (Bar-On, 2000; Van Rooyen \& Partners, 2000).

\section{Procedure}

The financial institution where the data were obtained requested, as part of its recruitment and its development purposes, that personnel in the managerial category complete the OPQ32i and EQ-i. The reliability of the data resides in the fact that the psychometric instruments were administered in a controlled test environment and were scored according to the procedures dictated by the providers of the psychometric instruments. In commencing the data collection, the researchers obtained a list of the individuals from the relevant psychometric Assessment Department in the managerial group that was required to complete the OPQ32i and EQ-i. The researchers contacted the participants to ensure their completion of both the OPQ32i and the EQ-i.

\section{Statistical analysis}

The statistical analysis involved intercorrelations being established and reported, where different variables were correlated to each other in order to establish the direction and magnitude of their relationship (Bailey, 1987). This method was used to test whether the relationship between stress management and emotional intelligence was positive and statistically significant. Multiple regression, using the step-wise method of regression, was calculated only where the independent variables that contributed significantly to predicting the dependent variable were included in the regression model. The method was used to test whether the prediction of stress management was increased when subscales of emotional intelligence were combined.

\section{RESULTS}

Table 1 illustrates the mean, minimum, maximum and standard deviation of the age, as well as the cumulative and percentage of the gender and ethnicity of the sample. It can be observed that the average age of the sample, less the age data of the two individuals, which were not available, is 36.00. Furthermore, the sample comprised $49.52 \%$ female and $50.48 \%$ male participants. The ethnicity grouping comprised coloureds, whites and African blacks witha representation of $13.33 \%$, $68.57 \%$ and $18.10 \%$, respectively.

Table 2 illustrates the mean, minimum, maximum and standard deviation of the scales of the dependent variable, stress management. It can be observed that four of the five scales, namely 'relaxed', 'tough minded', 'optimistic' and 'socially confident', are higher than 10.00 , with the scale of worrying the lowest, at 8.84 .

Table 3 illustrates the mean, minimum, maximum and standard deviation of the scales of the dependent variable, stress management, in comparison with the managerial and professional group $(\mathrm{N}=329)$.

In comparison with the managerial and professional-norm 
TABLE 1

Descriptive statistics of sample

\begin{tabular}{|c|c|c|c|c|c|c|}
\hline AGE & $\mathrm{N}$ & MEAN & MINIMUM & MAXIMUM & STD. DEV. & \\
\hline Age & 103 & 36.00 & 21.00 & 53.00 & 6.21 & \\
\hline GENDER & COUNT & CUMULATIVE & PERCENTAGE & CUMULATIVE \% & $\%$ OF ALL & CUMULATIVE \% \\
\hline Female & 52 & 52 & 49.52 & 49.52 & 49.52 & 49.52 \\
\hline Male & 53 & 105 & 50.48 & 100.00 & 50.48 & 100.00 \\
\hline ETHNICITY & COUNT & CUMULATIVE & PERCENTAGE & CUMULATIVE \% & $\%$ OF ALL & CUMULATIVE \% \\
\hline Coloured & 14 & 14 & 13.33 & 13.33 & 13.33 & 13.33 \\
\hline White & 72 & 86 & 68.57 & 81.90 & 68.57 & 81.90 \\
\hline African & 19 & 105 & 18.10 & 100.00 & 18.10 & 100.00 \\
\hline
\end{tabular}

TABLE 2

Descriptive statistics of the dependent variable, Stress Management $(n=105)$

\begin{tabular}{|c|c|c|c|c|c|c|}
\hline & MEAN & MINIMUM & MAXIMUM & STD. DEV. & SKEWNESS & KURTOSIS \\
\hline FE 1: Relaxed & 10.55 & 0.00 & 21.00 & 4.38 & 0.00 & -0.40 \\
\hline FE 2: Worrying & 8.84 & 1.00 & 23.00 & 5.07 & 0.56 & -0.34 \\
\hline FE 3: Tough-minded & 10.88 & 2.00 & 22.00 & 4.14 & 0.16 & -0.18 \\
\hline FE 4: Optimistic & 16.69 & 5.00 & 25.00 & 3.82 & -0.34 & 0.27 \\
\hline RP 7: Socially confident & 11.89 & 2.00 & 21.00 & 4.52 & -0.24 & -0.65 \\
\hline
\end{tabular}

TABLE 3

Descriptive statistics of the stress management obtained $(n=105)$ in comparison with the managerial and professional norm group $(n=329)$

\begin{tabular}{|c|c|c|c|c|c|c|c|}
\hline & MEAN & MINIMUM & MAXIMUM & STD. DEV. & MEAN & STD. DEV. & D-STATISTIC \\
\hline FE 1: Relaxed & 10.55 & 0.00 & 21.00 & 4.38 & 10.3 & 5.4 & 0.05 \\
\hline FE 2: Worrying & 8.84 & 1.00 & 23.00 & 5.07 & 11.8 & 5.8 & -0.53 \\
\hline FE 3: Tough-minded & 10.88 & 2.00 & 22.00 & 4.14 & 10.8 & 4.9 & 0.02 \\
\hline FE 4: Optimistic & 16.69 & 5.00 & 25.00 & 3.82 & 15.1 & 4.5 & 0.37 \\
\hline FE 7: Socially confident & 11.89 & 2.00 & 21.00 & 4.52 & 15.4 & 4.0 & -0.12 \\
\hline
\end{tabular}

group reflected in Table 3, it can be observed that the means of the relaxed, tough minded and optimistic scales of the norm group compare with the mean scales of the sample. The mean on the scale of worrying, however, is lower than the mean of the norm group. According to Cohen (1988), small-effect size $\mathrm{d}=.2$, medium-effect size $d=.3$ and equal and large-effect size $d=.5$. The medium-effect size difference between the two groups with regard to the worrying scale indicates that the sample tends to worry less than the norm group. The socially confident scale did not reflect any significant effect size.

Table 4 illustrates the mean, minimum, maximum and standard deviation of the scales of emotional intelligence, which is the independent variable. The means of four of the five total scales, namely total intrapersonal scales, total adaptability scales, total stress-management scales and total general-mood scales, are above 100, with the lowest scale (98.75) being the interpersonal scale. The mean of the EQ-i is 100, indicating that the total interpersonal scale is below the mean of the norm group and thus implying that the subscales of empathy, social responsibility and interpersonal relations for the sample group tend to be lower compared to those of the norm group.

With regard to the intercorrelation of the scales of stress management and emotional intelligence (Table 5), there is a significant correlation between the worrying scale of stress management and 12 of the emotional-intelligence scales (excluded were social responsibility, empathy and impulse control), the relaxed scale of stress management and stress tolerance, the tough-minded scale of stress management and flexibility, the optimistic scale of stress management and eight emotional-intelligence scales (self-regard, assertiveness, self-actualisation, empathy, interpersonal relations, stress tolerance, optimism and happiness), the socially confident scale of stress management and six scales of emotional intelligence (self-regard, emotional self-awareness, assertiveness, interpersonal relations, stress tolerance and happiness).
TABLE 4

Descriptive statistics of the independent variable, Emotional Intelligence $(n=105)$

\begin{tabular}{|c|c|c|c|c|}
\hline & MEAN & MINIMUM & MAXIMUM & $\begin{array}{l}\text { STD. } \\
\text { DEV. }\end{array}$ \\
\hline Self-regard & 102.88 & 64 & 125 & 11.39 \\
\hline Emotional self-awareness & 103.10 & 57 & 128 & 14.69 \\
\hline Assertiveness & 104.52 & 62 & 129 & 14.18 \\
\hline Independence & 101.92 & 62 & 126 & 13.89 \\
\hline Self-actualisation & 102.63 & 71 & 124 & 12.27 \\
\hline Total intrapersonal scales & 103.84 & 68 & 125 & 12.27 \\
\hline Empathy & 99.10 & 51 & 128 & 15.26 \\
\hline Social responsibility & 97.18 & 60 & 122 & 13.81 \\
\hline Interpersonal relations & 99.30 & 56 & 123 & 13.07 \\
\hline Total interpersonal scales & 98.75 & 65 & 125 & 12.31 \\
\hline Reality testing & 102.57 & 69 & 128 & 13.82 \\
\hline Flexibility & 104.55 & 65 & 130 & 13.76 \\
\hline Problem solving & 103.27 & 57 & 126 & 13.72 \\
\hline Total adaptability scales & 104.22 & 76 & 132 & 12.75 \\
\hline Stress tolerance & 104.78 & 71 & 127 & 12.22 \\
\hline Impulse control & 100.99 & 63 & 127 & 12.56 \\
\hline Total stress-management scales & 103.14 & 79 & 127 & 11.18 \\
\hline Optimism & 102.25 & 58 & 121 & 12.49 \\
\hline Happiness & 102.69 & 65 & 121 & 11.67 \\
\hline Total general-mood scales & 102.40 & 56 & 120 & 11.60 \\
\hline TOTAL EQ-I & 102.97 & 72 & 125 & 11.51 \\
\hline
\end{tabular}

The highest variance obtained was $42 \%$. Seven variables determined the variance of the worrying scale of the stressmanagement scale, namely stress tolerance, assertiveness, impulse control, empathy, reality testing, emotional selfawareness and self-regard. These data parallel the results of the correlation data, where a significant correlation was obtained between the worrying scales of stress management and 12 of the emotional-intelligence scales. 
TABLE 5

Intercorrelation of the scales of stress management and emotional intelligence $(\mathrm{N}=105)$

\begin{tabular}{|c|c|c|c|c|c|}
\hline & RELAXED & WORRYING & TOUGH-MINDED & OPTIMISTIC & $\begin{array}{r}\text { SOCIALLY } \\
\text { CONFIDENT }\end{array}$ \\
\hline Self-regard & 0.150 & $-0.43^{* *}$ & -0.10 & $0.25^{\star \star}$ & $0.34^{* *}$ \\
\hline Emotional self-awareness & 0.010 & $-0.41^{* *}$ & 0.18 & 0.14 & $0.41^{* *}$ \\
\hline Assertiveness & -0.020 & $-0.50^{* *}$ & 0.02 & $0.22^{*}$ & $0.38^{\star *}$ \\
\hline Independence & 0.010 & $-0.38^{\star *}$ & -0.06 & 0.16 & 0.10 \\
\hline Self-actualisation & -0.040 & $-0.46^{\star *}$ & -0.04 & $0.23^{*}$ & 0.18 \\
\hline Total intrapersonal scales & 0.050 & $-0.57^{* *}$ & 0.01 & $0.25^{*}$ & $0.38^{* *}$ \\
\hline Empathy & 0.020 & 0.17 & 0.02 & $0.19^{*}$ & 0.02 \\
\hline Social responsibility & -0.030 & -0.03 & 0.02 & 0.04 & -0.10 \\
\hline Interpersonal relations & -0.037 & $-0.36^{* *}$ & -0.07 & $0.20^{*}$ & $0.42^{* *}$ \\
\hline Total interpersonal scales & -0.040 & $-0.26^{\star *}$ & -0.03 & 0.19 & $0.21^{*}$ \\
\hline Reality testing & 0.020 & $-0.29^{* *}$ & 0.14 & -0.12 & 0.07 \\
\hline Flexibility & -0.030 & $-0.43^{* *}$ & $0.26^{* *}$ & 0.10 & 0.15 \\
\hline Problem solving & -0.037 & $-0.21^{\star *}$ & 0.02 & -0.10 & -0.06 \\
\hline Total adaptability scales & -0.040 & $-0.39^{* *}$ & 0.17 & -0.04 & 0.07 \\
\hline Stress tolerance & $0.250^{*}$ & $-0.58^{* *}$ & 0.09 & $0.20^{*}$ & $0.20^{*}$ \\
\hline Impulse control & 0.180 & 0.00 & 0.13 & 0.02 & 0.04 \\
\hline Total stress-management scales & $0.260^{* *}$ & $-0.35^{\star *}$ & 0.14 & 0.13 & 0.16 \\
\hline Optimism & 0.080 & $-0.42^{\star *}$ & 0.01 & $0.45^{* *}$ & 0.15 \\
\hline Happiness & 0.070 & $-0.45^{\star *}$ & $-0.16^{* *}$ & $0.29^{\star *}$ & $0.31^{* *}$ \\
\hline Total general-mood scales & 0.070 & $-0.47^{\star *}$ & -0.10 & $0.42^{* *}$ & $0.25^{*}$ \\
\hline TOTAL EQ-I & 0.090 & $-0.53^{\star *}$ & 0.05 & $0.24^{*}$ & $0.29^{* *}$ \\
\hline
\end{tabular}

Correlation is significant at $p<0.05$

${ }^{* *}$ Correlation is significant at $p<0.01$

A variance of $28 \%$ was identified for the socially confident scale of stress management, with eight variables explaining the variance of $28 \%$, namely interpersonal relations, emotional self-awareness, empathy, self-regard, problem solving, impulse control, assertiveness and flexibility. With the exception of the problem-solving, impulse-control and flexibility scales, the remainder of the results of the multiple regressions parallel those of the correlation studies above.

A variance of $20 \%$ of the relaxed scale, $17 \%$ of the optimistic scale and $14 \%$ of the tough-minded scale was further identified. These results confirm our hypothesis, which states that a combination of the emotional-intelligence scales, rather than each on its own, leads to a stronger and more significant prediction of the relaxed scale, worrying scale, tough-minded scale, optimistic scale and socially confident scale.

\section{DISCUSSION}

Mayer and Salovey (1997) regard emotional intelligence as a mental ability, Goleman (1998) regards it as everything but IQ and Bar-On (1997) regards it as an array of non-cognitive capabilities, competencies and skills that influence success in coping with environmental demands and pressures. From the various definitions of stress, the researchers conclude that the definition of stress comprises the following: demands or perceived stressors on a person; individual characteristics, skills and abilities to meet demands; the cognitive appraisal or interpretation of a situation; and the outcomes of behaviour (psychological, physiological, disease and observable behaviour). The 'individual characteristics, skills, abilities to meet the demands and cognitive appraisal or interpretation of the situation' reflect the mental and mixed models of emotional intelligence, while the 'demands on the person or perceived stressors' and 'the outcomes of the behaviour (psychological, physiological, disease and observable behaviour)' reflect the stress aspect of stress. In evaluating the relationship between emotional intelligence and stress management, the researchers are thus of the opinion that stress management (the ability to cope with stress) is a component of emotional intelligence, while stress can be either an input or an outflow of emotional intelligence or the lack thereof.

In critically evaluating the empirical results of the stressmanagement scales and the emotional-intelligence scales, the researchers observed the significant correlations of the worrying, optimistic and socially confident scales with the emotional-intelligence scales. The results support the researchers' view that stress management, which is coping with stress by being 'optimistic' and 'socially confident', is a component of emotional intelligence, while 'worry' can be either an input or an outflow of emotional intelligence or a lack thereof. In the researchers' opinion, their research therefore contributes to the growing understanding of the many facets of emotional intelligence.

Further research can be conducted to explore the same relationship between emotional intelligence and stress management. It is recommended that such research be conducted with a larger sample size to make the results more generalisable to a larger population.

There are also three key findings that can be recommended to the organisation in which the research was conducted. These findings are very relevant, as the sample group comprised a managerial group, which has a significant influence on staff morale. The findings are (1) the development of emotional intelligence as a skill for coping with stress, (2) a more in-depth use of psychometric instruments, namely the OPQ32i and the EQ-i, to ascertain developmental areas in the arenas of stress management and (3) the development of the levels of empathy, social responsibility and interpersonal relationships of the sample group.

The organisation currently uses management programmes that focus on the theory of stress, symptoms of stress and reactions to stress, rather than attempting to pre-empt stress by encouraging an understanding of emotional intelligence as a prerequisite to understanding reactions to stress. It is therefore recommended that emotional intelligence be developed as a skill to aid in coping with stress. 
The concepts of self-regard, emotional self-awareness, assertiveness, independence, self-actualisation, interpersonal relations, reality testing, flexibility, problem solving, stress tolerance, optimism, happiness, social responsibility, empathy and impulse control should be included in emotionalintelligence training for such training to be more effective. Ideally, this should lead to a solid understanding of emotional intelligence and better management of stress.

Psychometric instruments (the OPQ32i and EQ-i) are currently seen as independent tools to assess personality and emotionalintelligence levels, respectively, within the organisation. It is recommended that further intercorrelated studies be conducted with these two instruments to conceptualise a more focused and rigorous development programme for the group of managers in order to target specific developmental areas in the arenas of stress management and emotional intelligence. For instance, the OPQ32i could indicate that a person has a tendency towards lower levels of social confidence on the OPQ32i scales and lower levels of assertiveness on the EQ-i scales. This would indicate that the person should attend assertiveness training, which might contribute to boosting her or his social-confidence levels and hence enhancing levels of emotional intelligence and allowing for better stress management.

The areas of empathy, social responsibility and interpersonal relationships of the sample group could furthermore be valuable to address. These should be included in the development plans of the sample group to facilitate personal growth. The areas of empathy and social responsibility could be cultivated by exposing managers to more community work under the banner of the organisation, simultaneously promoting the organisation's commitment to community development. Alternatively, managers could work within the organisation, alternating between the department that deals with the wellbeing of employees and their own departments. This would enhance interpersonal skills, although the researchers are of the opinion that courses targeted to develop interpersonal skills, added to practical experience, would be more beneficial.

\section{REFERENCES}

Appelbaum, S.A. (1973). Psychological mindedness: Word, concept, and essence. International Journal of Psycho-Analysis, $54,35-46$.

Babbie, E. (1986). The practice of social research. (4th edn.). Chicago: Wadsworth.

Bailey, K.D. (1987). Methods of social research. (3rd edn.). London: The Free Press.

Bar-On, R. (1997). Bar-On Emotional Quotient Inventory (EQ-i): Technical manual. Toronto: Multi-Health Systems.

Bar-On, R. (2000). Emotional and social intelligence: Insights from the Emotional Quotient Inventory. In R. Bar-On \& J.D.A. Parker (Eds.), The handbook of emotional intelligence: Theory, development, assessment, and the application at home, school and in the workplace (pp. 363-388). San Francisco: Jossey-Bass Inc.

Bar-On, R. (2006). The Bar-On model of emotional-social intelligence (ESI). Psicothema, 18, 13-25.

Cascio, W.F. (2001). Knowledge creation for practical solutions appropriate to a changing world of work. South African Journal of Industrial Psychology, 27(4), 14-16.

Caruso, D.R., Mayer, J.D., \& Salovey, P. (2002). Emotional intelligence and emotional leadership. In R.E. Riggio \& S.E. Murphy (Eds.), Multiple intelligences and leadership (pp. 5573). Mahwah: Erlbaum.

Cohen, J. (1988). Statistical power analysis for the behavioural sciences (2nd edn.). Hillsdale: Lawrence Erlbaum, Associates.

Cox, T. (1985). The nature and measurement of stress. Ergonomics, $28(8), 1155-1163$.

Darwin, C. (1872/1965). The expression of the emotions in man and animals. Chicago: University of Chicago Press.

Goleman, D. (1995). Emotional Intelligence. New York: Bantam Publishers.
Goleman, D. (1998). Working with emotional intelligence. London: Bloomsbury Publishing plc.

Goleman, D., Boyatzis, R., \& McKee, A. (2002). The new leaders: Transforming the art of leadership into the science of results. London: Time Warner Paperbacks.

Grout, J. (1994). Executive stress and how to survive it. Executive Development, 7(4), 29-30.

Hellgren, J., Naswell, K., \& Sverke, M. (2005). There's more to the picture than meets the eye: A comparison of downsizing survivors with changed and unchanged job content. South African Journal of Industrial Psychology, 31(4), 87-93.

Higgs, M. (2002). How can we make sense of leadership in the 21st century? Leadership \& Organisation Development Journal, 25(5), 273-284.

Hopkins, M.M.,O'Neil, D.A., \& Williams, H.W. (2007). Emotional intelligence and board governance: Leadership lessons from the public sector. Journal of Managerial Psychology, 22(7), 683-700

Huifang, Y., \& Jianping, G. (2007). Research on the emotional intelligence, self-efficacy and achievement motivation of business managers. Psychological Science, 30(3), 719-722.

Jamali, D., Sidani, Y., \& Abu-Zaki, D. (2008). Emotional intelligence and manement development implications: Insights from the Lebanese context. Journal of Management Development, 27(3), 348-360.

Langley, A. (2000). Emotional intelligence - a new evaluation for management development? Career Development International, 5(3), 177-183.

Lazarus, R.S., \& Folkman, S. (1984). Stress, appraisal, and coping. New York: Springer.

Lopes, P., \& Salovey, P. (2004). Toward a broader education: Social, emotional and practical skills. In P. Salovey, M.A. Brackett \& J.D. Mayer (Eds.), Emotional intelligence: Key readings on the Mayer and Salovey model (pp. 287-303). New York: Dude Publishing.

Matthews, G., \& Zeidner, M. (2000). Emotional intelligence, adaptation to stressful encounters, and health outcomes. In R. Bar-On \& J.D.A. Parker (Eds.), The handbook of emotional intelligence: Theory, development, assessment, and the application at home, school and in the workplace (pp. 459-489). San Francisco: Jossey-Bass Inc.

Mayer, J.D., \& Salovey, P. (1997). Emotional development and emotional intelligence: Educational implications. In P. Salovey, M.A. Brackett \& J.D. Mayer (Eds.), Emotional intelligence: Key readings on the Mayer and Salovey model (pp. 29-60). New York: Dude Publishing.

Mayer, J.D., Cobb, C.D., \& Casey, D. (2000a). Educational policy on emotional intelligence: Does it make sense? In P. Salovey, M.A. Brackett \& J.D. Mayer (Eds.), Emotional intelligence: Key readings on the Mayer and Salovey Model (pp. 265-285). New York: Dude Publishing.

Mayer, J.D., Salovey, P., \& Caruso, D.R. (2000b). Emotional intelligence as Zeitgeist, as personality, and as a mental ability. In R. Bar-On \& J.D.A. Parker (Eds.), The handbook of emotional intelligence: Theory, development, assessment, and the application at home, school and in the workplace (pp. 92-117). San Fransisco: Jossey-Bass Inc.

McCallum, M., \& Piper, W.E. (2000). Psychological mindedness and emotional intelligence. In R. Bar-On \& J.D.A. Parker (Eds.), The handbook of emotional intelligence: Theory, development, assessment, and the application at home, school and in the workplace (pp. 118-135). San Francisco: Jossey-Bass Inc.

McCrae, R.R. (2000). Emotional intelligence from the perspective of the five-factor model of personality. In R. Bar-On \& J.D.A. Parker (Eds.), The handbook of emotional intelligence: Theory, development, assessment, and the application at home, school and in the workplace (pp. 263-276). San Fransisco: Jossey-Bass Inc.

Mikolajczak, M., \& Luminet, O. (2008). Trait emotional intelligence and the cognitive appraisal of stressful events: An exploratory study. Personality and Individual Differences, $44(7), 1445-1453$. 
Mikolajczak, M., Menil, C., \& Luminet, O. (2007a). Explaining the protective effect of trait emotional intelligence regarding occupational stress: Exploration of emotional labour processes. Journal of Research in Personality, 41(5), 1107-1117.

Mikolajczak, M., Roy, E., Luminet, O., Fillée, C., \& De Timary, P. (2007b). The moderating impact of emotional intelligence on free cortisol responses to stress. Psychoneuroendocrinology, 32(8-10), 1000-1012.

Montes-Berges, B., \& Augusto, J.M. (2007). Exploring the relationship between perceived emotional intelligence, coping, social support and mental health in nursing students. Journal of Psychiatric and Mental Health Nursing, 14(2), 163-171.

Ndlouvu, N., \& Parumasur, S.B. (2005). The perceived impact of downsizing and organisational transformation on survivors. South African Journal of Industrial Psychology, 31(2), 14-21.

Nevid, J.S., Rathus, S.A., \& Greene, B. (2005). Abnormal psychology in a changing world media and research update. Upper Saddle River: Prentice Hall.

Pike, A. (2003). Dealing with stress: Health and safety. Emergency Services $S A, 24(5), 20-21$.

Ramos, N.S., Fernandez-Berrocal, P., \& Extremera, N. (2007). Perceived emotional intelligence facilitates cognitiveemotional processes of adaptation to an acute stressor. Cognition E Emotion, 21(4), 758-772.

Rees, W.D. (1997). Managerial stress - dealing with the causes, not the symptoms. Industrial and Commercial Training, 29(2), $35-40$.

Saarni, C. (2000). Emotional competence: A developmental perspective. In R. Bar-On \& J.D.A. Parker (Eds.), The handbook of emotional intelligence: Theory, development, assessment, and the application at home, school and in the workplace (pp. 68-91). San Francisco: Jossey-Bass Inc.

Salovey, P., Brackett, M.A., \& Mayer, J.D. (2004). Emotional intelligence: Key readings on the Mayer and Salovey model. New York: Dude Publishing.

Salovey, P., \& Mayer, J.D. (1990). Imagination, cognition, and personality. In P. Salovey, M.A. Brackett \& J.D. Mayer (Eds.), Emotional intelligence: Key readings on the Mayer and Salovey model (pp. 1-27). New York: Dude Publishing.
SHL. (1999a). Course notes. Surrey: SHL Group plc.

SHL. (1999b). OPQ32 manual and user's guide. Surrey: SHL Group plc.

SHL. (2006). OPQ32 technical manual. Surrey: SHL Group plc.

Sifneos, P.E. (1967). Clinical observations on some patients suffering from a variety of psychosomatic diseases. Acta Medicina Psychosomatica, 21, 133-136.

Strümpfer, D.J.W. (2003). Resilience and burnout: A stitch that could save nine. South African Journal of Psychology, 33(2), $69-79$.

Taylor, G.J., \& Bagby, R.M. (2000). An overview of the alexithymia construct. In R. Bar-On \& J.D.A. Parker (Eds.), The handbook of emotional intelligence: Theory, development, assessment, and the application at home, school and in the workplace (pp. 40-67). San Francisco: Jossey-Bass Inc.

Thorndike, E.L. (1920). Intelligence and its uses. Harper's Magazine, 140, 227-235.

Van Rooyen, J., \& Partners. (2000). Bar-On EQ-i training manual. Adapted from Multi Health Systems (MHS), Canada.

Vermeulen, L.P. (2002). A comparison of reasons and objectives for organisational downsizing in South Africa and Australia. Journal of the Southern African Institute for Management Scientists, 11(2), 28-39.

Wechsler, D. (1940). Nonintellective factors in general intelligence. Psychological Bulletin, 37, 444-445.

Wechsler, D. (1943). Nonintellective factors in general intelligence. Journal of Abnormal Social Psychology, 38, 100104.

Wiese, L., Rothmann, S., \& Storm, K. (2003). Coping, stress and burnout in the South African Police Service in KwaZuluNatal. South African Journal of Industrial Psychology, 29(4), $71-80$.

Yang, H., \& Gu, J. (2007). Research on the emotional intelligence, self-efficacy and achievement motivation of business managers. Psychological Science, 30(3), 719-722.

Zeidner, M., \& Saklofske, D.S. (1996). Adaptive and maladaptive coping. In M. Zeidner \& N.S. Endler (Eds.), Handbook of coping (pp. 505-531). New York: Wiley. 